\title{
Conventional and 24-h ambulatory blood pressure as independent predictors of elastic arterial properties
}

\author{
Barbara Wizner ${ }^{\mathrm{a}, \mathrm{b}}$, Dirk G. Dechering ${ }^{\mathrm{c}}$, Lutgarde Thijs ${ }^{\mathrm{a}}$, Tatiana Kuznetsova ${ }^{\mathrm{a}}$, \\ Tom Richart ${ }^{a, e}$, Yu Jin ${ }^{a}$, Jerzy Gąsowski ${ }^{b}$, Eoin O'Brien ${ }^{f}$, \\ Harry A. Struijker-Boudier ${ }^{d}$, Tomasz Grodzicki ${ }^{b}$ and Jan A. Staessen ${ }^{a, e}$
}

\begin{abstract}
Objective No population study investigated whether 24-h ambulatory blood pressure (ABP) predicts distensibility of the elastic common carotid (DCar) and the muscular femoral (DFem) arteries over and beyond conventionally measured blood pressure (СВP).
\end{abstract}

Methods At baseline, we measured CBP and 24-h ABP in 1063 randomly recruited participants (mean age, 44.3 years). CBP was the average of five consecutive readings obtained by trained observers at the participants' homes. We measured arterial distensibility by a wall-tracking ultrasound system, 21 months after CBP and ABP (5-95th percentile interval range, 13-33 months).

Results Compared with men, women (49.2\%) had higher $(P<0.03) \mathrm{DCar}\left(24.7 \mathrm{vs.} 23.3 \times 10^{-3} / \mathrm{kPa}\right)$ and higher DFem (10.6 vs. $\left.9.2 \times 10^{-3} / \mathrm{kPa}\right)$. In multivariate-adjusted models, including both CBP and ABP and stratified by sex, DCar was negatively related to systolic, diastolic, and mean arterial CBP in both sexes, and to diastolic ABP in women. $D F e m$ was inversely correlated with diastolic $A B P$ in both sexes and with systolic and mean arterial $A B P$ in men. Moreover, DFem was also negatively correlated with systolic and mean arterial CBP in men. In most instances, pulse pressure on CBP or ABP measurement did not predict DCar or DFem. No evidence of influential collinearity between $\mathrm{CBP}$ and $\mathrm{ABP}$ was observed.

\section{Introduction}

The consensus view is that automated techniques of blood pressure measurement, such as ambulatory monitoring or self-measurement at home, provide more accurate estimates of a patient's blood pressure than conventional measurement at the office [1,2]. Consequently, ambulatory blood pressure and self-measured blood pressure at home are better predictors of cardiovascular complications than office blood pressure measurement [3-8]. Currently, a few outcome studies compared the predictive value of the 24-h ambulatory blood pressure with that of highly standardized blood pressure measurements obtained by a trained observer in the home environment [9].

The 2007 guidelines of the European Society of Hypertension carefully reviewed the evidence that arterial properties can be an intermediate endpoint in randomized clinical
Conclusion Depending on vascular territory, there is competition between highly standardized CBP and ABP in predicting DCar and DFem. These findings show that CBP under standardized conditions, and subject to rigorous quality control, is equally predictive of the elastic properties of large arteries as ABP. Blood Press Monit 14:12-19 $\odot 2009$ Wolters Kluwer Health | Lippincott Williams \& Wilkins.

Blood Pressure Monitoring 2009, 14:12-19

Keywords: arterial compliance, blood pressure measurement, blood pressure monitoring, population science, risk factors

${ }^{a}$ Department of Cardiovascular Diseases, Division of Hypertension and Cardiovascular Rehabilitation, Studies Coordinating Centre, University of Leuven, Leuven, Belgium, ${ }^{\text {b }}$ Department of Internal Medicine and Gerontology, Jagiellonian University Medical College, Kraków, Poland, 'Department of General Internal Medicine, University Medical Centre St Radboud, Radboud University, Nijmegen, ${ }^{\mathrm{d} D e p a r t m e n t}$ of Pharmacology and Toxicology, Cardiovascular Research Institute, eDepartment of Epidemiology University of Maastricht, Maastricht,

The Netherlands and ${ }^{f}$ Conway Institute of Biomolecular and Biomedical Research, University College Dublin, Dublin, Ireland

Correspondence to Professor Jan A. Staessen, MD, PhD, Studies Coordinating Centre, Division of Hypertension and Cardiovascular Rehabilitation, Department of Cardiovascular Diseases, University of Leuven, Campus Gasthuisberg, Herestraat 49, PO Box 702, Leuven B-3000, Belgium

Tel: +32 1634 7104; fax: +32 16347106 ;

e-mail: jan.staessen@med.kuleuven.be

Received 4 June 2008 Revised 29 July 2008 Accepted 7 August 2008

trials of antihypertensive drugs [1]. Moreover, several longitudinal studies in populations $[10,11]$ or hypertensive patients [12-16] showed that increased arterial stiffness leads to worse cardiovascular outcome. To our knowledge, no earlier population-based studies compared the relationship of arterial properties with conventional and ambulatory blood pressure measurements. The purpose of this study was to investigate whether 24-h ambulatory blood pressure monitoring at baseline predicted the elastic properties of the common carotid and femoral arteries over and beyond highly standardized blood pressure measurements obtained by skilled observers at the participants' homes.

\section{Methods}

Study population

The Flemish Study on Environment, Genes, and Health Outcomes is a part of the European Project on Genes in 
Hypertension. Starting from August 1985, we recruited a random sample of families from a geographically defined area in Northern Belgium [17]. The ethics committee of the University of Leuven approved the study. All participants gave written informed consent. The initial participation rate averaged $64.3 \%$.

For a measurement of the elastic arterial properties, we reinvited 1322 former participants whose blood pressure had previously been measured at home and by 24-h ambulatory monitoring (1991-2001). Of these 1322 participants, we excluded 259, because they were younger than 18 years $(n=91)$, because they did not have measurements at both the common carotid and femoral arteries $(n=154)$, or because their blood pressure measurements or their arterial properties were more than three standard deviations above the population mean $(n=14)$. Thus, the number of participants statistically analyzed totaled 1063 .

\section{Blood pressure measurement at baseline (1991-2001)}

As described elsewhere, the nurses involved in blood pressure measurement participated in a standardized quality assurance and quality control program of their blood pressure readings [18,19]. Every 3 months, the accuracy of their blood pressure readings was checked, by using a video movie showing a falling mercury column with Korotkoff sounds, and by simultaneous blood pressure measurements by the nurses and physicians on life subjects. To pass the test, the film readings and measurements of the nurses had to be within $5 \mathrm{mmHg}$ of the standard for the video or the physicians' readings. Nurses, who failed the test, were given additional training until they met the quality standards. The trained nurses visited the participants at home [19]. After the participants had rested in the sitting position for $5 \mathrm{~min}$, the nurses obtained five consecutive blood pressure readings to the nearest $2 \mathrm{mmHg}$ (phase $\mathrm{V}$ diastolic) by conventional sphygmomanometry. During the measurements, the participant's arm was supported at heart level. In most participants, standard cuffs with a $22 \times 12 \mathrm{~cm}$ bladder were used. If arm circumference exceeded $31 \mathrm{~cm}$, larger cuffs with a $35 \times 15 \mathrm{~cm}$ bladder were applied. For analysis, we averaged the five blood pressure readings obtained at home. Hypertension was conventionally obtained blood pressure of at least $140 \mathrm{mmHg}$ systolic or $90 \mathrm{mmHg}$ diastolic or the use of antihypertensive medication.

On a separate day, validated oscilometric SpaceLabs 90202 and 90207 monitors [20] (Redmond, Washington, USA), fitted with the same cuff size as for the conventionally measured blood pressure at home, were programmed to obtain readings with an interval of $20 \mathrm{~min}$ from $8: 00 \mathrm{~h}$ until $22: 00 \mathrm{~h}$, and every $45 \mathrm{~min}$ from $22: 00 \mathrm{~h}$ to $8: 00 \mathrm{~h}$. The calibration of these devices was checked on a monthly basis against a mercury column. If the ambulatory recordings were longer than 1 day, only the first $24 \mathrm{~h}$ were analyzed. Intraindividual means of the ambulatory measurements were weighed by the time interval between successive readings [19]. Pulse pressure was systolic minus diastolic blood pressure. Mean arterial pressure was directly measured by the oscilometric SpaceLabs recorders, and calculated as diastolic pressure plus one-third of pulse pressure for conventional measurements.

\section{Arterial ultrasound examination at follow-up (1992-2003)}

For at least $3 \mathrm{~h}$ before the vascular examination, the participants refrained from smoking, heavy exercise, and alcohol-containing or caffeine-containing beverages. By means of a pulsed ultrasound wall-tracking system (Wall Track System; Pie Medical, Maastricht, The Netherlands), three trained researchers obtained vascular measurements at the common carotid artery $2 \mathrm{~cm}$ proximal of the carotid bulb, at the femoral artery $1 \mathrm{~cm}$ proximal of the bifurcation into the profound and superficial branches, and at the right brachial artery $2 \mathrm{~cm}$ proximal of the antecubital fossa. As described elsewhere [21], the observers applied applanation tonometry with a pencil-shaped probe (Millar Instruments Inc., Houston, Texas, USA) and calibration to mean and diastolic pressure at the brachial artery to derive the local pulse pressure at the other arteries. We computed the distensibility coefficient (DC) and the cross-sectional compliance (CC) from the diastolic crosssectional area $(A)$, the systolic increase in the crosssectional area $(\Delta A)$, and the local pulse pressure $(\Delta P)$ [22]: $\mathrm{DC}=(\Delta A / A) / \Delta P$ and $\mathrm{CC}=\Delta A / \Delta P . A$ and $\Delta A$ were calculated as $A=\pi \times(D / 2)^{2}$ and $\Delta A=\pi \times[(D+\Delta D) / 2]^{2}$ $-\pi \times(D / 2)^{2}$. The intraobserver intrasession variability was less than $10 \%$ for the carotid measurements, and amounted to $10-15 \%$ for femoral DC and CG [23]. The intraobserver intersession and interobserver intrasession variability were of the same order of magnitude [23].

\section{Other measurements}

The nurses administered the same questionnaire at baseline and follow-up to collect information about the participants' medical history, smoking and drinking habits, and intake of medications. In addition, the nurses measured the participants' anthropometric characteristics. Body mass index was weight in kilograms divided by height in meters squared.

At baseline, we took a blood sample for the measurement of serum total and high-density lipoprotein (HDL) cholesterol, blood glucose, and serum creatinine. Diabetes mellitus was a self-reported diagnosis, a fasting or random blood glucose level of at least $7.0 \mathrm{mmol} / \mathrm{l}$ $(126 \mathrm{mg} / \mathrm{dl})$ or $11.1 \mathrm{mmol} / \mathrm{l}(200 \mathrm{mg} / \mathrm{dl})$, respectively, or 
the use of antidiabetic drugs [24]. Hypercholesterolemia was a total cholesterol level of at least $5.16 \mathrm{mmol} / \mathrm{l}$ $(200 \mathrm{mg} / \mathrm{dl})$ or the use of lipid-lowering drugs [25].

\section{Statistical analysis}

For database management and statistical analysis, we used SAS software, version 9.1.3 (SAS Institute Inc., Cary, North Carolina, USA). We analyzed women and men separately, because their blood pressure (Table 1) and elastic arterial properties (Table 2) differed significantly. We compared means and proportions by the standard

Table 1 Baseline characteristics by sex

\begin{tabular}{|c|c|c|c|}
\hline & $\begin{array}{l}\text { Women } \\
(n=526)\end{array}$ & $\begin{array}{c}\text { Men } \\
(n=537)\end{array}$ & $P$ \\
\hline Age (years) & $44.7 \pm 13.7$ & $44.2 \pm 13.7$ & 0.44 \\
\hline Body mass index $\left(\mathrm{kg} / \mathrm{m}^{2}\right)$ & $24.7 \pm 4.3$ & $25.6 \pm 3.3$ & $<0.0001$ \\
\hline \multicolumn{4}{|l|}{$\begin{array}{l}\text { Blood pressure measurements } \\
(\mathrm{mmHg})\end{array}$} \\
\hline Conventional systolic & $121.6 \pm 15.9$ & $126.2 \pm 13.4$ & $<0.0001$ \\
\hline Conventional diastolic & $76.2 \pm 10.1$ & $79.2 \pm 10.3$ & $<0.0001$ \\
\hline Conventional MAP & $91.4 \pm 11.2$ & $94.9 \pm 10.2$ & $<0.0001$ \\
\hline Conventional pulse pressure & $45.4 \pm 11.2$ & $47.0 \pm 10.9$ & 0.02 \\
\hline 24-h systolic & $119.1 \pm 11.7$ & $123.7 \pm 10.7$ & $<0.0001$ \\
\hline 24-h diastolic & $73.4 \pm 8.9$ & $75.8 \pm 8.5$ & $<0.0001$ \\
\hline 24-h MAP & $88.7 \pm 9.4$ & $91.0 \pm 8.4$ & $<0.0001$ \\
\hline 24-h pulse pressure & $45.7 \pm 7.9$ & $47.9 \pm 8.0$ & $<0.0001$ \\
\hline Pulse rate $24-\mathrm{h}$ (beats/min) & $77.9 \pm 10.8$ & $71.3 \pm 10.6$ & $<0.0001$ \\
\hline \multicolumn{4}{|l|}{ Biochemical measurements } \\
\hline Total cholesterol (mmol/l) & $5.55 \pm 1.06$ & $5.50 \pm 1.11$ & 0.45 \\
\hline HDL-cholesterol (mmol/l) & $1.58 \pm 0.39$ & $1.20 \pm 0.31$ & $<0.0001$ \\
\hline Total/HDL cholesterol ratio & $3.74 \pm 1.23$ & $4.94 \pm 2.20$ & $<0.0001$ \\
\hline Serum creatinine $(\mu \mathrm{mol} / \mathrm{l})$ & $79.6 \pm 12.87$ & $96.1 \pm 13.49$ & $<0.0001$ \\
\hline Blood glucose $(\mathrm{mmol} / \mathrm{l})$ & $4.82 \pm 1.05$ & $4.87 \pm 1.16$ & 0.49 \\
\hline \multicolumn{4}{|l|}{ Other cardiovascular risk factors } \\
\hline Current smoking, $n(\%)$ & $159(30.2)$ & $173(32.2)$ & 0.47 \\
\hline Current drinking, $n(\%)$ & $85(16.1)$ & $224(41.7)$ & $<0.0001$ \\
\hline Diabetes, $n(\%)$ & $5(1.0)$ & $8(1.5)$ & 0.42 \\
\hline Hypertension, $n(\%)$ & $119(22.6)$ & $148(27.6)$ & 0.06 \\
\hline Antihypertensive therapy, $n(\%)$ & $64(12.1)$ & $54(10.1)$ & 0.28 \\
\hline Cardiovascular diseases, $n(\%)$ & $32(3.0)$ & $32(6.0)$ & 0.94 \\
\hline Hypercholesterolemia, $n(\%)$ & $351(66.7)$ & $346(64.4)$ & 0.44 \\
\hline Lipid-lowering drugs, $n$ (\%) & $17(3.2)$ & $13(2.4)$ & 0.65 \\
\hline $\begin{array}{l}\text { Oral contraceptive pill in women, } \\
n(\%)\end{array}$ & $118(22.4)$ & - & - \\
\hline Hormonal therapy, $n(\%)$ & $13(2.5)$ & - & - \\
\hline
\end{tabular}

Data are mean \pm SD or number of participants (\%). The conventional blood pressure was the average of five readings obtained by an observer at the participants' homes.

HDL, high-density lipoprotein; MAP, mean arterial pressure.

Table 2 Arterial elastic properties by sex

\begin{tabular}{lccc}
\hline & $\begin{array}{c}\text { Women } \\
(n=526)\end{array}$ & $\begin{array}{c}\text { Men } \\
(n=537)\end{array}$ & $P$ \\
\hline Common carotid artery & & & \\
$\quad$ Diameter $(\mathrm{mm})$ & $6.8 \pm 0.8$ & $7.6 \pm 0.9$ & $<0.0001$ \\
$\quad$ Distensibility $\left(10^{-3} / \mathrm{kPa}\right)$ & $24.7 \pm 11.9$ & $23.3 \pm 9.2$ & 0.027 \\
Compliance coefficient $\left(\mathrm{mm}^{2} / \mathrm{kPa}\right)$ & $0.89 \pm 0.39$ & $1.04 \pm 0.40$ & $<0.0001$ \\
$\quad$ Local pulse pressure $\left(\mathrm{mmHg}^{2}\right)$ & $46.6 \pm 12.2$ & $48.3 \pm 12.5$ & 0.022 \\
Femoral artery & & & \\
$\quad$ Diameter $(\mathrm{mm})$ & $8.5 \pm 1.2$ & $9.9 \pm 1.5$ & $<0.0001$ \\
$\quad$ Distensibility $\left(10^{-3} / \mathrm{kPa}\right)$ & $10.6 \pm 6.4$ & $9.2 \pm 5.4$ & $<0.0001$ \\
Compliance coefficient $\left(\mathrm{mm}^{2} / \mathrm{kPa}\right)$ & $0.59 \pm 0.34$ & $0.71 \pm 0.44$ & $<0.0001$ \\
Local pulse pressure $(\mathrm{mmHg})$ & $51.1 \pm 12.5$ & $54.0 \pm 12.7$ & 0.0002 \\
\hline
\end{tabular}

Data are mean \pm SD. normal $\approx$ test and the $\chi^{2}$ statistic, respectively. We used McNemar's test for the pairwise comparison of proportions. Our statistical methods also included single and multiple linear regressions. Significant covariates of the vascular measurements were traced by a stepwise regression procedure. We set the $P$ value for variables to enter and stay in the model at 0.10 . We estimated the effect size of blood pressure on the arterial properties by using standardized regression coefficients. Covariates considered for entry into the model were observer $(n=3)$, and baseline characteristics, including age, body mass index, current smoking, intake of alcohol, and antihypertensive drug treatment.

In sensitivity analyses, we forced additional baseline covariates into the models, including the total-to-HDLcholesterol ratio in serum, blood glucose, serum creatinine, earlier history of cardiovascular disease, and in women also the use of oral contraceptives and/or hormonal replacement therapy. Furthermore, we also forced changes in the cardiovascular risk profile from baseline to follow-up into the models. Statistical significance was a two-sided $P$ value of 0.05 .

\section{Results \\ Characteristics of the participants at baseline}

The 1063 participants included 526 women (49.5\%); 267 hypertensive patients (25.1\%) of whom 118 (44.2\%) were on antihypertensive drug treatment; and $643(60.5 \%)$ hypercholesterolemic patients, of whom $30(2.8 \%)$ were on lipid-lowering drugs. Women compared with men (Table 1), had lower conventional and ambulatory blood pressures and less frequently reported intake of alcohol $(P<0.0001)$. In drinkers, the median daily alcohol consumption was $16 \mathrm{~g}$. The prevalence of smoking was similar in both sexes (Table 1). In smokers, the median tobacco use was 15 cigarettes per day $(5-95$ th percentile interval, 3-30). Among 350 premenopausal and 176 postmenopausal women, $118(33.8 \%)$ and $13(7.4 \%)$ used oral contraceptives or hormonal replacement therapy, respectively. Table 2 presents the arterial properties by sex and vascular territory. Figure 1 shows the sex-specific associations of arterial distensibility with age; Fig. 2 presents similar information by quartiles of the conventional and 24-h ambulatory blood pressures.

\section{Quality control of blood pressure measurement}

The eight observers involved in the study measured blood pressure at home in 1063 participants, and obtained 5315 readings of both systolic and diastolic blood pressures. For systolic blood pressure, six observers did not show any number preference, that is, repetition of the same blood pressure value within each series of five consecutive measurements in 657 participants. Two other observers showed number preference in five of 92 participants (5.4\%) and in 10 of 314 participants (3.2\%), 
Fig. 1

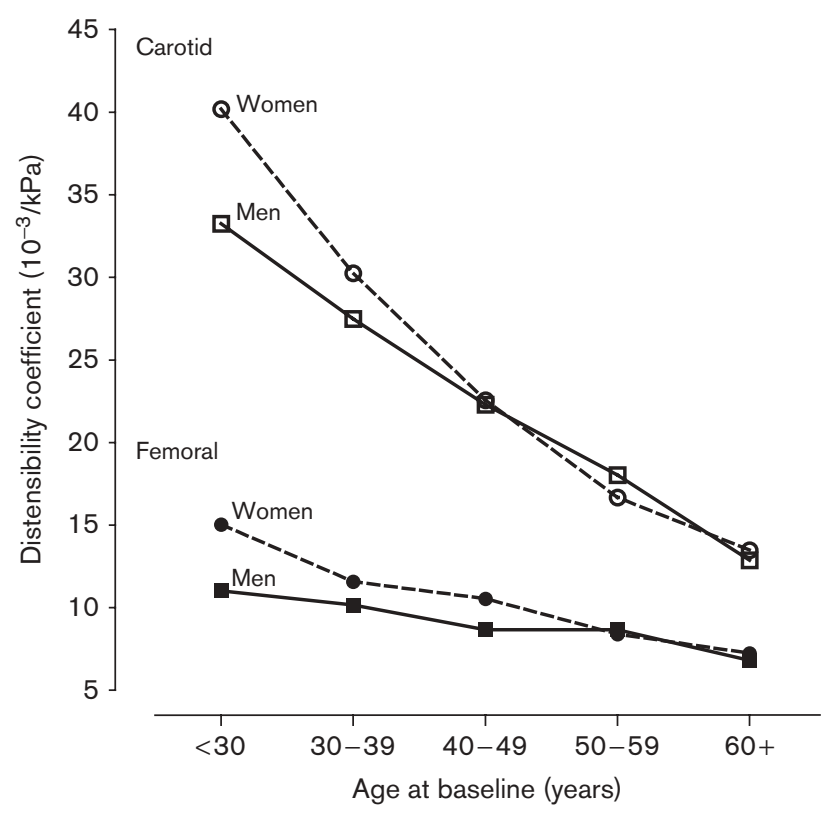

Associations of arterial distensibility with age by sex.

respectively. For diastolic blood pressure, four observers did not show any number preference in 533 participants. The other four observers repeated the same values within a series of five measurements, in two of 78 participants (2.6\%), in two of 92 participants $(2.2 \%)$, in 13 of 314 participants (4.1\%), and in six of 46 participants (13.0\%). In terms of digit preference, among the eight observers, there was an overrepresentation (expected 20\%) of a terminal zero, amounting to $4.7 \%(P<0.0001)$ for systolic pressure and to $6.7 \%(P<0.0001)$ for diastolic pressure. No significant differences in the frequencies of systolic values ending on $2,4,6$, or $8(P=0.97)$ were observed. For diastolic blood pressure there was an underrepresentation of values ending on 2,4 , and 6 (approximately 2.5\%; $P<0.0001$ ). Of the 10630 readings, six $(0.06 \%)$ for systolic and three $(0.03 \%)$ for diastolic blood pressure ended on an uneven number.

The 1063 ambulatory blood pressure recordings spanned a median of $22 \mathrm{~h}$ (5-95th percentile interval, 20-24; interquartile range 21-23). The median number of readings per recording was 44 (5-95th percentile interval, 32-59; interquartile range $40-56$ readings).

\section{Arterial distensibility in relation to the conventional and 24-h blood pressures}

In keeping with earlier analyses [26], stepwise regression identified the following covariates as significantly related to the arterial properties in women and men: age, body mass index, smoking and drinking habits, and antihypertensive drug treatment. We therefore adjusted all analyses for these covariates, and in addition for observer.

Both before (Fig. 2) and after adjustment (Table 3) for the aforementioned covariates, systolic and diastolic blood pressures and mean arterial pressure predicted the distensibility of the common carotid and femoral arteries in women and men, irrespective of whether blood pressure was measured conventionally or by 24-h ambulatory monitoring. The only exception was the association between femoral distensibility in women and diastolic blood pressure on conventional measurement $(P=0.08$; Table 3). Both before and after adjustment, pulse pressure was not a strong predictor of arterial distensibility (Table 3 ). The adjusted associations were only significant for femoral distensibility in relation to the conventional pulse pressure in both sexes, and for femoral distensibility in relation to the 24-h ambulatory blood pressure in men.

In fully adjusted models, we next adjusted the conventional blood pressure for the equivalent 24-h ambulatory blood pressure, and vice versa. In these analyses, depending on arterial territory, there was competition between the conventional and ambulatory blood pressures in predicting arterial distensibility (Table 3). The distensibility of the common carotid artery remained consistently and negatively related to the conventional measurements of systolic and diastolic blood pressure and mean arterial pressure in women as well as in men. In contrast, in fully adjusted models, femoral distensibility was inversely related with the 24-h diastolic blood pressure in both sexes and with systolic and mean arterial pressure in men.

In some instances, such as for carotid distensibility in relation to diastolic blood pressure in women and for femoral distensibility in relation to systolic blood pressure and mean arterial pressure in men, both conventional and ambulatory measurements were predictive. In none of the aforementioned models, the condition index exceeded 36.0, excluding influential collinearity between the conventional and ambulatory blood pressures. The results for the CC coefficients of the common carotid and femoral arteries were not materially different from those of the DCs.

\section{Sensitivity analyses}

The median interval between the blood pressure measurement at baseline and the arterial ultrasound examination was 21 months (5-95th percentile interval, 13-33 months). From baseline to the vascular examination, body mass index increased by $0.17 \mathrm{~kg} / \mathrm{m}^{2}(95 \%$ confidence interval: $0.05-0.28 ; P=0.004)$ in men, and by $0.22 \mathrm{~kg} / \mathrm{m}^{2}$ (confidence interval: $0.08-0.35 ; P=0.002$ ) in women. Prevalences during the examination visit were: 
Fig. 2
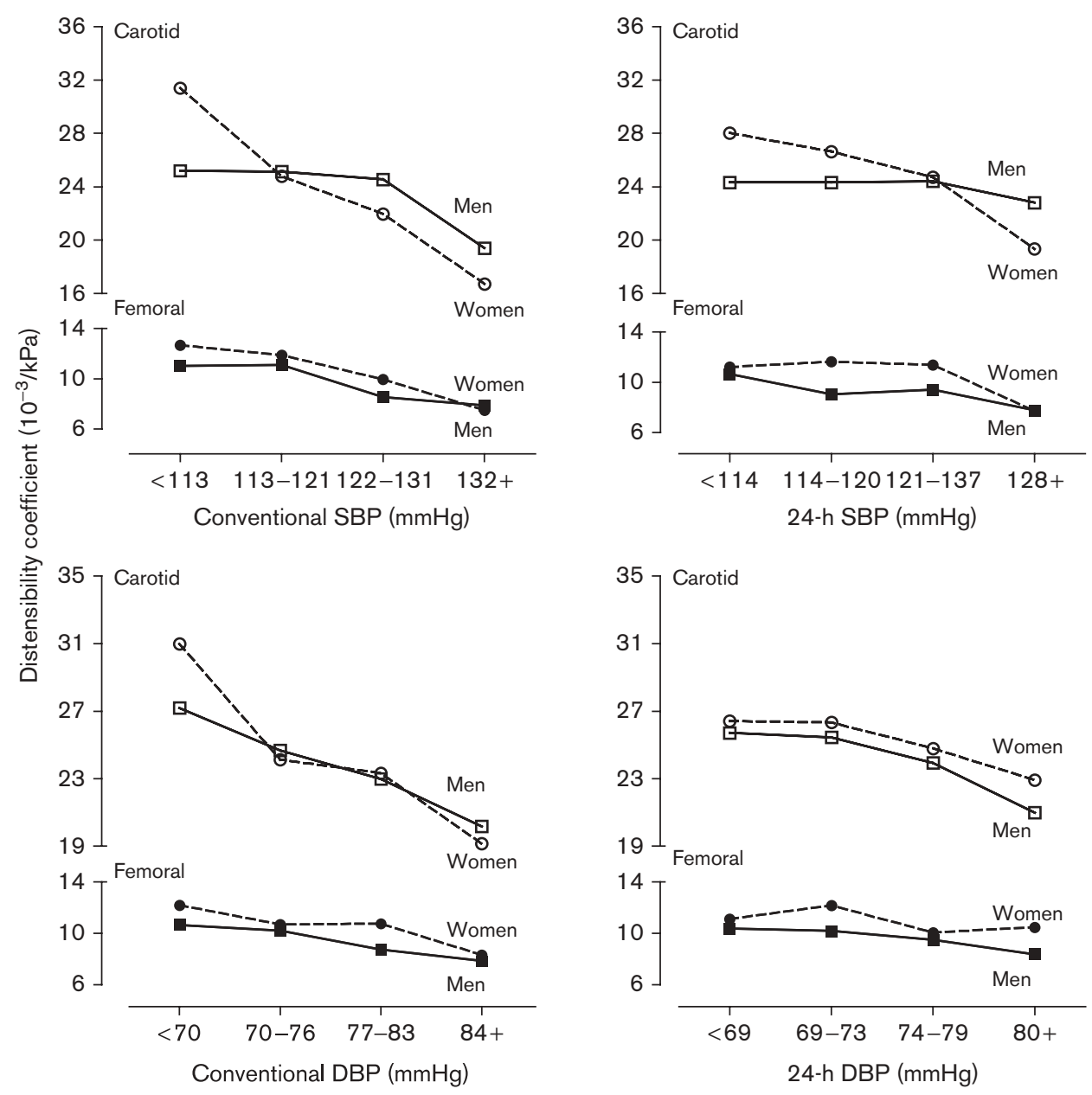

Arterial distensibility by quartiles of blood pressure and sex. DBP, diastolic blood pressure; SBP, systolic blood pressure.

$30.5 \%$ ( $n=324 ; P$ value for comparison with baseline, $0.32)$ for smoking; 45.3\% $(n=482 ; P<0.0001)$ for drinking alcohol; $3.0 \%(n=32 ; P=0.0006)$ for a history of cardiovascular disease; $13.6 \%(n=145 ; P=0.0002)$ for the use of antihypertensive drugs; and $4.2 \% \quad(n=45$; $P=0.02$ ) for the intake of lipid-lowering drugs. From baseline to follow-up, the percentage of women taking contraceptive pills decreased by about a half (22.4 vs. $12.0 \% ; P<0.0001$ ), but the proportion of women on hormonal substitution therapy remained unchanged (2.5 vs. $1.9 \% ; P=0.26)$. Our results remained consistent, when we forced the following covariates into the regression models: the ratio of total-to-HDL-cholesterol in serum, blood glucose, serum creatinine, earlier history of cardiovascular disease, and the use of female steroid hormones. Moreover, when we additionally adjusted our models for changes in body mass index from baseline to follow-up, duration of follow-up, and changes in smoking habits, treatment status (antihypertensive and lipidlowering drugs, and female steroid hormones), our results remained unaltered.

\section{Discussion}

The key finding of our study was that highly standardized conventional blood pressure readings performed by skilled observers in the relaxed home environment were, in general, equally predictive of arterial distensibility as the 24-h ambulatory blood pressure. The predictive value of both types of blood pressure measurement varied by vascular territory, sex, and blood pressure component. In general, systolic, diastolic, and mean arterial pressure were strong predictors of arterial distensibility, irrespective of the type of blood pressure measurement, whereas pulse pressure was only a weak predictor. To our knowledge, ours is the first population-based study addressing the 
Table 3 Adjusted and fully adjusted standardized regression coefficients of arterial distensibility with conventional and 24-h blood pressure components

\begin{tabular}{|c|c|c|c|c|c|c|c|c|}
\hline & \multicolumn{4}{|c|}{ Common carotid distensibility } & \multicolumn{4}{|c|}{ Femoral distensibility } \\
\hline & \multicolumn{2}{|c|}{ Women } & \multicolumn{2}{|c|}{ Men } & \multicolumn{2}{|c|}{ Women } & \multicolumn{2}{|c|}{ Men } \\
\hline & $\beta \pm S E$ & $P$ & $\beta \pm \mathrm{SE}$ & $P$ & $\beta \pm S E$ & $P$ & $\beta \pm S E$ & $P$ \\
\hline \multicolumn{9}{|l|}{ Systolic pressure } \\
\hline Adjusted conventional & $-1.77 \pm 0.41$ & $<0.0001$ & $-1.14 \pm 0.37$ & 0.002 & $-0.99 \pm 0.29$ & 0.0007 & $-1.17 \pm 0.26$ & $<0.0001$ \\
\hline Adjusted 24-h & $-1.48 \pm 0.41$ & 0.0003 & $-0.98 \pm 0.37$ & 0.009 & $-0.71 \pm 0.28$ & 0.014 & $-1.23 \pm 0.25$ & $<0.0001$ \\
\hline Fully adjusted conventional & $-1.37 \pm 0.54$ & 0.012 & $-0.86 \pm 0.45$ & 0.056 & $-0.90 \pm 0.38$ & 0.019 & $-0.69 \pm 0.30$ & 0.025 \\
\hline Fully adjusted 24-h & $-0.60 \pm 0.53$ & 0.26 & $-0.50 \pm 0.45$ & 0.27 & $-0.13 \pm 0.37$ & 0.72 & $-0.85 \pm 0.30$ & 0.005 \\
\hline \multicolumn{9}{|l|}{ Diastolic pressure } \\
\hline Adjusted conventional & $-1.82 \pm 0.40$ & $<0.0001$ & $-1.65 \pm 0.32$ & $<0.0001$ & $-0.49 \pm 0.28$ & 0.08 & $-0.65 \pm 0.23$ & 0.004 \\
\hline Adjusted 24-hour & $-1.66 \pm 0.39$ & $<0.0001$ & $-1.47 \pm 0.36$ & $<0.0001$ & $-0.80 \pm 0.27$ & 0.003 & $-0.89 \pm 0.25$ & 0.0004 \\
\hline Fully adjusted conventional & $-1.28 \pm 0.47$ & 0.007 & $-1.32 \pm 0.37$ & 0.0005 & $0.0001 \pm 0.34$ & 0.99 & $-0.33 \pm 0.26$ & 0.21 \\
\hline Fully adjusted 24-h & $-0.97 \pm 0.46$ & 0.037 & $-0.71 \pm 0.42$ & 0.088 & $-0.77 \pm 0.33$ & 0.018 & $-0.70 \pm 0.29$ & 0.016 \\
\hline \multicolumn{9}{|l|}{ Mean arterial pressure } \\
\hline Adjusted conventional & $-1.99 \pm 0.40$ & $<0.0001$ & $-1.71 \pm 0.35$ & $<0.0001$ & $-0.76 \pm 0.29$ & 0.008 & $-0.98 \pm 0.24$ & $<0.0001$ \\
\hline Adjusted 24-h & $-1.63 \pm 0.39$ & $<0.0001$ & $-1.33 \pm 0.38$ & 0.0005 & $-0.79 \pm 0.28$ & 0.004 & $-1.06 \pm 0.26$ & $<0.0001$ \\
\hline Fully adjusted conventional & $-1.54 \pm 0.52$ & 0.003 & $-1.47 \pm 0.42$ & 0.0005 & $-0.41 \pm 0.37$ & 0.27 & $-0.63 \pm 0.29$ & 0.030 \\
\hline Fully adjusted 24-h & $-0.69 \pm 0.50$ & 0.17 & $-0.48 \pm 0.45$ & 0.28 & $-0.54 \pm 0.36$ & 0.13 & $-0.70 \pm 0.31$ & 0.024 \\
\hline \multicolumn{9}{|l|}{ Pulse pressure } \\
\hline Adjusted conventional & $-0.56 \pm 0.41$ & 0.17 & $0.33 \pm 0.33$ & 0.31 & $-0.81 \pm 0.28$ & 0.004 & $-0.60 \pm 0.23$ & 0.008 \\
\hline Adjusted 24-h & $-0.18 \pm 0.41$ & 0.66 & $0.19 \pm 0.33$ & 0.56 & $-0.07 \pm 0.28$ & 0.80 & $-0.60 \pm 0.23$ & 0.008 \\
\hline Fully adjusted conventional & $-0.60 \pm 0.46$ & 0.19 & $0.32 \pm 0.38$ & 0.40 & $-0.97 \pm 0.32$ & 0.002 & $-0.40 \pm 0.26$ & 0.13 \\
\hline Fully adjusted 24-h & $0.08 \pm 0.45$ & 0.85 & $0.03 \pm 0.38$ & 0.94 & $0.35 \pm 0.31$ & 0.26 & $-0.40 \pm 0.26$ & 0.12 \\
\hline
\end{tabular}

$\beta$, standardized regression coefficient; the units of $\beta$ are $10^{-3} / \mathrm{kPa}$ per $1 \mathrm{SD}$ increase in the blood pressure component as reported in Table 1. Adjusted for observers and baseline characteristics: age, body mass index, smoking and drinking habits, and antihypertensive treatment. Fully adjusted means conventional blood pressure additionally adjusted for 24 -h ambulatory blood pressure and vice versa.

association between arterial distensibility and the conventional as compared with the ambulatory blood pressure. The median interval between the arterial examination and the blood pressure measurements was 21 months.

Our current results are in line with an earlier study of 391 patients (mean age, 71 years) [9], which compared the predictive value of the conventional blood pressure measured at home by a general practitioner with that of the ambulatory blood pressure. During a median followup of 10.9 years, 86 patients (22\%) suffered a cardiovascular event. The adjusted relative hazard ratios associated with a 1-SD increment in systolic blood pressure were similar for the conventional, daytime, and nighttime blood pressure (1.32, 1.33, 1.42, respectively). Most other studies on the association of arterial properties with various types of blood pressure measurement were cross-sectional [27-29] and involved selected hypertensive patients $[8,30]$ or compared the office blood pressure with the self-measured blood pressure at home $[8,31]$ or with the $24-\mathrm{h}$ ambulatory blood pressure [8,27]. Jula et al. [32] studied 233 referred hypertensive patients, who were all off treatment. A trained nurse measured the clinic blood pressures. Two readings at four visits were averaged for analysis. The home blood pressure in this Finnish study was the average of two readings in the morning and two in the evening on 7 consecutive days. The home blood pressure was selfrecorded with a semiautomatic oscilometric device. The unadjusted Pearson's correlation coefficients of clinic, home, and 24-h blood pressures with albuminuria and left ventricular mass index were nearly equal. On the basis of these cross-sectional findings, the Finnish investigators [32] concluded that carefully controlled nonphysicianmeasured clinic and self-measured home blood pressures were as reliable as the ambulatory blood pressure in the clinical evaluation of untreated hypertension.

Numerous studies compared conventional and ambulatory blood pressure measurements for association with intermediate or hard cardiovascular endpoints in a crosssectional or longitudinal manner. A few of these studies, however, if any, reported on the quality of the conventional blood pressure readings [18,33-35], whereas measurement of the 24-h ambulatory blood pressure was generally well standardized. The quality of the conventional blood pressure readings in our study was high. At screening in the Second Australian National Blood Pressure Study [35], observers obtained three consecutive measurements of blood pressure, by using a standard mercury sphygmomanometer as in this study. For both systolic and diastolic blood pressures, observed digit preference fell within $7 \%$ of the expected frequency. The Australian investigators did not report on number preference. In an observational study conducted as multiple standardized audits in general practice in Merseyside (United Kingdom) [33], 86\% of all systolic blood pressures and $77 \%$ of diastolic pressures ended in zero. In the Systolic Hypertension in Europe Trial [36], the prevalence of the use of terminal digit zero while measuring sitting systolic blood pressure (first readings) reduced from an average of $42.4 \%$ in the year before the date when a center first randomized a patient to 31.5, 25.0, $22.3,26.3,23.2$, and $22.0 \%$ in the subsequent 6 years. This 
trend was independent of the calendar year during which a center entered the trial and supports the hypothesis that data-quality monitoring, including the feedback regarding digit preference to centers, led to a reduction in terminal digit zero preference. In addition, a higher-than-expected prevalence of the systolic blood pressure value of $148 \mathrm{mmHg}$ was found in the double-blind phase. Selection for $148 \mathrm{mmHg}$ persisted over time and constituted a singlenumber preference bias. This arose from the instruction to investigators to reduce systolic blood pressure to below $150 \mathrm{mmHg}$.

In 28-47 hypertensive patients recruited in the framework of the European Lacidipine Study on Atherosclerosis [37], blood pressure at enrollment was measured both by mercury sphygmomanometer (three readings [38]) and by 24-h ambulatory monitoring. During the run-in period, carotid distensibility was measured with the same wall-tracking system as in this study. Radial distensibility was measured by means of an ultrasonic device (NIUS 02 , Omega, Bienne, Switzerland). In unadjusted crosssectional analyses, carotid distensibility showed negative correlations of about the same magnitude with both office and 24-h systolic blood pressures $(r=-0.45$, and -0.58 , respectively; $P<0.008)$. Adjustment for age removed the significant correlation with the office blood pressure $(r=-0.33 ; P=0.06)$, but not with the 24 -h systolic blood pressure $(r=-0.44 ; P=0.02)$. Radial distensibility was not associated with blood pressure, irrespective of the type of measurement.

This study must be interpreted within the context of some potential limitations. First, the observer-made blood pressure readings in the relaxed home environment are different from the conventional blood pressure measured in a medical setting, as well as from the self-measured blood pressure at home. Therefore, our current findings cannot be extrapolated to these other types of blood pressure measurement. Second, a quality control program of conventional blood pressure measurements, as set up in this study, might be difficult, if not impossible, to implement in routine clinical practice. Self-measurement of blood pressure at home by means of validated automated devices might be a more practicable approach. Third, at variance with earlier reports [27-29], our study had a longitudinal design. Several studies $[39,40]$ showed that arterial remodeling occurs in elastic [39] and muscular arteries [40,41] within a few weeks [41] to 6 months [39] after an alteration of the hemodynamic loading conditions. Cardiovascular risk factors changed during the 21-month interval (median) between the blood pressure measurement at baseline and the ultrasound examination of the carotid and femoral arteries at followup. Our findings, however, remained basically unchanged in fully adjusted models, in which we accounted for timerelated changes in cardiovascular risk profile.
In conclusion, depending on vascular territory, there is a competition between highly standardized conventional blood pressure measurements and the 24-h ambulatory blood pressure in predicting the distensibility of the carotid and femoral arteries. These findings show that the conventional blood pressure under standardized conditions, and subject to rigorous quality control, is an equally strong predictor of the elastic properties of large arteries as the 24-h ambulatory blood pressure.

\section{Acknowledgments}

The authors gratefully acknowledge the expert technical assistance of Sandra Covens and Ya Zhu (Studies Coordinating Centre, University of Leuven, Belgium). The European Union (grants IC15-CT98-0329-EPOGH, LSHM-CT-2006-037093 InGenious HyperCare, and HEALTH-F4-2007-201550 HyperGenes), the Fonds voor Wetenschappelijk Onderzoek Vlaanderen, Ministry of the Flemish Community, Brussels, Belgium (grants G.0424.03, G.0453.05 and G.0575.06), and the University of Leuven, Belgium (grants OT/99/28, OT/00/25 and OT/05/49) gave support to the Studies Coordinating Centre. The bilateral scientific and technological collaboration between Poland and Flanders, Ministry of the Flemish Community, Brussels (grant BIL/05/22) supported the fellowship of B.W. in Leuven. The Dutch Heart Foundation (Dr. E. Dekker grant), Den Haag, The Netherlands, supported the fellowship of D.G.D. The authors declare that they have no conflict of interest.

\section{References}

1 Mancia G, De Backer G, Dominiczak A, Cifkova R, Fagard R, Germano G, et al. 2007 Guidelines for the management of arterial hypertension. The task force for the management of arterial hypertension of the European Society of Hypertension (ESH) and of the European Society of Cardiology (ESC). $J$ Hypertens 2007; 25:1105-1187.

2 O'Brien E, Asmar R, Beilin L, Imai Y, Mancia G, Mengden T, et al. Practice guidelines of the European Society of Hypertension for clinic, ambulatory and self blood pressure measurement. J Hypertens 2005; 23:697-701.

3 Mancia G, Zanchetti A, Agebiti-Rosei E, Benemio G, De Cesaris R, Fogari R, et al. Ambulatory blood pressure is superior to clinic blood pressure in predicting treatment-induced regression of left ventricular hypertrophy. Circulation 1997; 95:1464-1470.

4 Staessen JA, Thijs L, Fagard R, O'Brien ET, Clement D, De Leeuw PW, et al. Predicting cardiovascular risk using conventional vs. ambulatory blood pressure in older patients with systolic hypertension. Systolic hypertension in Europe trial investigators. JAMA 1999; 282:539-546.

5 Verdecchia P, Reboldi G, Porcellati C, Schillaci G, Pede S, Bentivoglio M, et al. Risk of cardiovascular disease in relation to achieved office and ambulatory blood pressure control in treated hypertensive subjects. J Am Coll Cardiol 2002; 39:878-885.

6 Hansen TW, Kikuya M, Thijs L, Bjorklund-Bodegard K, Kuznetsova T, Ohkubo T, et al. Prognostic superiority of daytime ambulatory over conventional blood pressure in four populations: a meta-analysis of 7030 individuals. $J$ Hypertens 2007; 25:1554-1564.

7 Niiranen TJ, Jula AM, Kantola IM, Karanko H, Reunanen A. Home-measured blood pressure is more strongly associated with electrocardiographic left ventricular hypertrophy than in clinic blood pressure: the Finn-HOME study. J Hum Hypertens 2007; 21:788-794.

8 Stergiou GS, Argyraki KK, Moyssakis I, Mastorantonakis SE, Achimastos AD Karamanos VG, et al. Home blood pressure is as reliable as ambulatory blood pressure in predicting target-organ damage in hypertension. Am J Hypertens 2007; 20:616-621. 
9 Fagard RH, Van Den Broecke C, De Cort P. Prognostic significance of blood pressure measured in the office, at home and during ambulatory monitoring in older patients in general practice. J Hum Hypertens 2005; 19:801-807.

10 Hansen TW, Staessen JA, Torp-Pedersen C, Rasmussen S, Thijs L, Ibsen H, et al. Prognostic value of aortic pulse wave velocity as index of arterial stiffness in the general population. Circulation 2006; 113:664-670.

11 Mattace-Raso FU, Van Der Cammen TJ, Hofman A, Van Popele NM, Bos ML, Schalekamp MA, et al. Arterial stiffness and risk of coronary heart disease and stroke: the Rotterdam study. Circulation 2006; 113:657-663.

12 Blacher J, Asmar R, Djane S, London GM, Safar ME. Aortic pulse wave velocity as a marker of cardiovascular risk in hypertensive patients. Hypertension 1999; 33:1111-1117.

13 Laurent S, Katsahian S, Fassot C, Tropeano Al, Gautier I, Laloux B, et al. Aortic stiffness is an independent predictor of fatal stroke in essential hypertension. Stroke 2003; 34:1203-1206.

14 Laurent S, Boutouyrie P, Asmar R, Gautier I, Laloux B, Guize L, et al. Aortic stiffness is an independent predictor of all-cause and cardiovascular mortality in hypertensive patients. Hypertension 2001; 37:1236-1241.

15 Gąsowski J, Fagard RH, Staessen JA, Grodzicki T, Pocock S, Boutitie F, et al. Pulsatile blood pressure component as predictor of mortality in hypertension: a meta-analysis of clinical trial control groups. $J$ Hypertens 2002; 20:145-151.

16 Dolan E, Thijs L, Li Y, Atkins N, McCormack P, McClory S, et al. Ambulatory arterial stiffness index as a predictor of cardiovascular mortality in the Dublin Outcome Study. Hypertension 2006; 47:365-370.

17 Staessen J, Bulpitt CJ, Fagard R, Joossens JV, Lijnen P, Amery A. Familial aggregation of blood pressure, anthropometric characteristics and urinary excretion of sodium and potassium-a population study in two Belgian towns. J Chronic Dis 1985; 38:397-407.

18 Kuznetsova T, Staessen JA, Kawecka-Jaszcz K, Babeanu S, Casiglia E, Filipovsky J, et al. Quality control of the blood pressure phenotype in the European Project on Genes in Hypertension. Blood Press Monit 2002; 7:215-224.

19 Staessen JA, Bieniaszewski L, O'Brien ET, Imai Y, Fagard R. An epidemiological approach to ambulatory blood pressure monitoring: the Belgian population study. Blood Press Monit 1996; 1:13-26.

20 O'Brien E, Waeber B, Parati G, Staessen J, Myers MG, on behalf of the European Society of Hypertension working group on ambulatory blood pressure monitoring. Blood pressure measuring devices: recommendations of the European Society of Hypertension. Br Med J 2001; 322:531-536.

21 Balkestein EJ, Wang JG, Struijker-Boudier HA, Barlassina C, Bianchi G, Birkenhager $\mathrm{WH}$, et al. Carotid and femoral intima-media thickness in relation to three candidate genes in a Caucasian population. $J$ Hypertens 2002; 20:1551-1561.

22 Hoeks APG, Reneman RS. Biophysical principles of vascular diagnosis. J Clin Ultrasound 1995; 23:71-79.

23 Kool MJF, Van Merode T, Reneman RS, Hoeks APG, Struijker Boudier HAJ, Van Bortel LMAB. Evaluation of the reproducibility of a vessel wall movement detector system for assessment of large artery properties. Cardiovasc Res $1994 ; 28: 610-614$

24 Expert committee on the diagnosis and classification of diabetes mellitus. Report of the expert committee on the diagnosis and classification of diabetes mellitus. Diab Care 2003; 26:S5-S20.

25 National Cholesterol Education Program (NCEP) expert panel on detection EaToHBCiAATPI. Third report of the National Cholesterol Education Program (NCEP) expert panel on detection, evaluation, and treatment of high blood cholesterol in adults (adult treatment panel III) final report. Circulation 2002; 106:3143-3421.

26 Zebekakis PE, Nawrot T, Thijs L, Balkestein EJ, Van Der Heijden-Spek J, Van Bortel L, et al. Obesity is associated with increased arterial stiffness from adolescence until old age. J Hypertens 2005; 23:1839-1846.

27 Shintani Y, Kikuya M, Hara A, Ohkubo T, Metoki H, Asayama K, et al. Ambulatory blood pressure, blood pressure variability and the prevalence of carotid artery alteration: the Ohasama study. J Hypertens 2007; 25:1704-1710.

28 Tsioufis C, Stefanadis C, Antoniadis D, Kallikazaros I, Zambaras P, Pitsavos C et al. Absence of any significant effects of circadian blood pressure variations on carotid artery elastic properties in essential hypertensive subjects. J Hum Hypertens 2000; 14:813-818.

29 Jerrard-Dunne P, Mahmud A, Feely J. Circadian blood pressure variation: relationship between dipper status and measures of arterial stiffness. $J$ Hypertens 2007; 25:1233-1239.

30 Zanchetti A, Crepaldi G, Bond MG, Gallus GV, Veglia F, Ventura A, et al. Systolic and pulse pressures (but not diastolic blood pressure and serum cholesterol) are associated with alterations in carotid intima-media thickness in the moderately hypercholesterolaemic hypertensive patients of the plaque hypertension lipid lowering Italian study. J Hypertens 2001; 19:79-88.

31 Niiranen T, Jula A, Kantola I, Moilanen L, Kahonen M, Kesaniemi YA, et al. Home-measured blood pressure is more strongly associated with atherosclerosis than clinic blood pressure: the Finn-HOME study. J Hypertens 2007; 25:1225-1231.

32 Jula A, Puukka P, Karanko H. Multiple clinic and home blood pressure measurements versus ambulatory blood pressure monitoring. Hypertension 1999; 34:261-266.

33 Cranney M, Barton S, Walley T. The management of hypertension in the elderly by general practitioners in Merseyside: the rule of halves revisited. Br J Gen Pract 1998; 48:1146-1150.

34 Yoshiike N, Nakayama T, Yokoyama T, Tanaka H, Labarthe DR. Quality control for blood pressure measurement in population studies: Shibata Children's Heart study. J Clin Epidemiol 1997; 50:1169-1173.

35 Reid CM, Ryan P, Miles H, Willson K, Beilin LJ, Brown MA, et al. Who's really hypertensive? Quality control issues in the assessment of blood pressure for randomized trials. Blood Press 2005; 14:133-138.

36 Wingfield D, Cooke J, Thijs L, Staessen JA, Fletcher AE, Fagard R, et al. Terminal digit preference and single-number preference in the Syst-Eur trial: influence of quality control. Blood Press Monit 2002; 7:169-177.

37 Giannattasio C, Failla M, Hennig M, Hollweck R, Laurent S, Mallion JM, et al Different relation between $24-\mathrm{h}$ blood pressure and distensibility at different peripheral arteries. Data from the European Lacidipine Study on Atherosclerosis (ELSA). J Hypertens 2005; 23:557-562.

38 Zanchetti A, Bond MG, Hennig M, Neiss A, Mancia G, Dal Palù C, et al. Risk factors associated with alterations in carotid intima-media thickness in hypertension: baseline data from the European Lacidipine Study on Atherosclerosis. J Hypertens 1998; 16:949-961.

39 Irace C, Gnasso A, Cirillo F, Leonardo G, Ciamei M, Crivaro A, et al. Arteria remodeling of the common carotid artery after aortic valve replacement in patients with aortic stenosis. Stroke 2002; 33:2446-2450.

40 Dinenno FA, Tanaka H, Monahan KD, Clevenger CM, Eskurza I, DeSouza CA, et al. Regular endurance training induces expansive arterial remodelling in the trained limbs of healthy men. J Physio/ 2001; 534:287-295.

41 De Groot PCE, Van Kuppevelt DHJM, Pons C, Snoek G, Van Der Woude LHV, Hopman MTE. Time course of arterial vascular adaptations to inactivity and paralyses in humans. Med Sci Sports Exerc 2003; 35:1977-1985. 